\title{
Russian Arctic ecosystem sustainability in rapid changes and challenges
}

\author{
Violetta Gassiy ${ }^{1, *}$, and Anatoliy Sleptsov ${ }^{2}$ \\ ${ }^{1}$ Kuban State University, 149 Stavropolskaya st., 350040 Krasnodar, Russia \\ ${ }^{2}$ North-Eastern Federal University, 58 Belinsky str., 677000 Yakutsk, Russia
}

\begin{abstract}
The issues of the ensuring of the Arctic ecosystem sustainability are considered in the paper. The authors research the main approaches to sustainable development policy implemented by the Arctic countries, including the Russian Federation. The relevance of the study is justified by the ongoing rapid changes in the Arctic space lead to negative consequences associated with the safety of human life in the northern regions. The article also substantiates the positive aspects of climate change and their impact on sustainable development. Based on statistical analysis, the authors identify the main trends in socio-economic and environmental changes in the Russian Arctic. The Conclusion outlines the directions for ensuring of ecosystem sustainable development, based on innovation, non-conflict coexistence of northern communities and business, the implementation of a rational state policy based on the balance of the economy, social sphere and natural capital.
\end{abstract}

\section{Introduction}

In 2021, the Russian Federation took over the chairmanship of the Arctic Council. This is an international platform where the Arctic countries interact to shape an agenda for political, economic, social and environmental cooperation. Having acted as the leader of the council, Russia announced the continuity of the programs of Finland and Iceland during their chairmanship of the Arctic Council. The main theme within which program activities will be formed is sustainable development and preservation of natural capital through the development of environmentally friendly technologies.

The industrial development of the Arctic region, which is moving further and further into the depths of untouched territories, leads to an imbalance in the ecosystem. Technogenic changes in the landscape have a negative impact on the pastures and the coastline. To a large extent, the problem of pollution in the Arctic is associated with water resources, maintaining the purity of rivers, and hence the World Ocean.

On the other hand, the huge reserves of hydrocarbons, which are hidden in the Arctic ice and on the mainland, are capable of ensuring the realization of Russia's national interests. This is possible thanks to large investment projects for the extraction of gas, oil, diamonds and gold, rare earth metals. Currently, our country is one of the leaders in the

* Corresponding author: vgassiy@mail.ru 
export of natural gas from the Arctic regions. Moreover, modern transportation technologies are actively developing. LGN is coming to the fore, and with it the need for innovation is growing.

In this regard, the role of non-Arctic countries is increasing in the extraction of natural resources, their processing and production of industrial products, as well as in participation in Arctic projects, logistics, etc. We are talking about countries such as Japan, China, South Korea, India. First of all, as energy dependent states, these countries are interested in the active development of the Arctic, gaining access to natural resources. The role of China is growing every year due to the growth of its economic influence on the world economy.

When considering the problems of sustainable development of the natural capital of the Arctic, it should be especially noted the need to comply with the requirements for the construction of investment facilities, transportation and life support infrastructure in the aspect of climatic changes to which this difficult and sensitive region is prone. In recent years, the impact of climate change on the Arctic territories has sharply increased. This phenomenon has both positive and negative consequences. In particular, the melting of permafrost leads to the degradation of infrastructure, destruction of buildings, pipelines, water logging of places intended for summer reindeer routes [1]. On the other hand, retreating permafrost makes deposits and transport routes more accessible, expanding human capabilities in the Arctic.

\section{Methods for sustainable development research of Arctic ecosystem}

The Arctic is a complex region where the interests of the Arctic and non-Arctic countries and business companies intersect. On this basis, the Arctic strategies of the participants in the development of the polar region form the approaches and mechanisms for the implementation of national and business interests. Currently, one of the important objects of discussion is the sustainable development of the Arctic, long-term programs for the conservation and restoration of its biodiversity, the introduction of innovations in industrial production based on the principles of a green economy. Of course, despite the differences in goals and approaches, the uniting principle of actors in the Arctic is its ecosystem, its resources, an understanding of the vulnerability of fragility and the high sensitivity of its elements.

The main intergovernmental organization whose purpose is to develop and support cooperation in the Arctic is the Arctic Council. Russia, as the chairing country 2021-2023, implements continuity in the area of the sustainable development agenda. The Sustainable Development Working Group implements programs in the field of non-carbon activity and building, economic development, business promotion based on the production of local types of goods, health and sanitation, etc. Impact assessments reports become the basis for the development of national policies, regional strategies, scientific research.

Programs aimed at supporting young people are especially important, since migration in the Arctic regions is negative. It is necessary to create conditions under which it would be beneficial for the local population not to leave their historical sites. This approach is associated, first of all, with the development of production of products of traditional nature management. This type of activity is life-supporting for indigenous peoples, therefore, the introduction of business approaches to traditional environmental management is a trend in the modern sustainable development of the Arctic communities. For example, projects on the implementation of the principles of a blue bioeconomy based on the rational use of water resources (Arctic seas and rivers) [2].

Methods for studying the problem of sustainable development of the Arctic ecosystem are a set of techniques and approaches to cognition of polar reality, processes occurring 
within the circumpolar space. The purpose of the study is to identify the problems of sustainable development of the Arctic ecosystem, as well as to develop proposals for improving the Arctic policy in this area. To achieve the goal, research methods can be represented by the following system (fig.1):

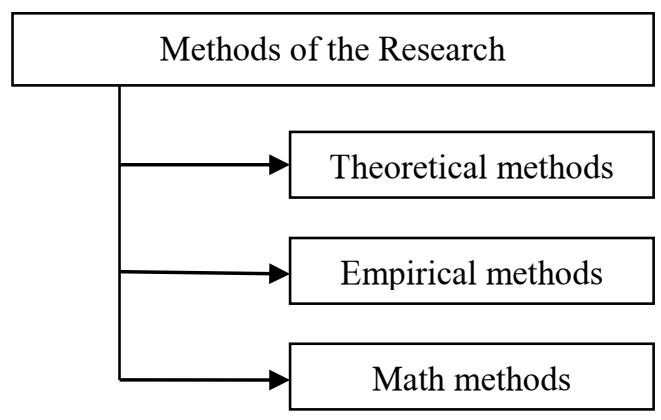

Fig. 1. Methods of the research

Theoretical research methods imply movement from simple to complex, analysis of the main sources on the topic of sustainable development of the Arctic, synthesis of existing approaches.

The empirical methods in this study are to compare the existing norms and practices in the field of sustainable development of the Arctic ecosystem.

Mathematical methods are based primarily on statistics, analysis of data on the dynamics of socio-economic and environmental indicators of sustainable development of the Arctic ecosystem.

Many scientific works are devoted to the study of Arctic changes and the problems of sustainable development. Threats and opportunities, prospects and limitations in connection with the transformation of the Arctic territories are reflected in publications on geology, biology, chemistry, physics, economics, social sciences, political science, etc. As A. Lynge writes, climatic changes have led to the fact that the circle of participants in Arctic research and directly living in polar conditions has expanded significantly [3].

A significant part of research in the field of sustainable development in the Arctic is devoted to the problems of interaction between local communities and industrial companies. Climate change leads to the expansion of industrial development of industrial areas, so it is important to take into account the interests of the local population in order to avoid conflicts. C. Southcott investigates the problems of management of territories of traditional nature use from the perspective of using the opportunities for benefit sharing. For example, the local population does not always fully know their rights, opportunities that can be used when interacting with business [4]. Therefore, partnership and cooperation of northern communities and businesses is a mechanism for ensuring sustainable development of Arctic ecosystems.

Finding solutions in the field of change management remains an important problem. Monz, C. A., Gutzwiller, K. J. Hausner, V. H., Brunson, M. W., Buckley, R., \& Pickering, C. M. write about the need to develop ecosystem-based adaptation strategies for sustainable development [5].

T. Koivurova considers the sustainable development of the Arctic ecosystem as a result of the interaction of business with the Arctic environment based on the principles of social responsibility [6]. Moreover, he believes that the trail of climate change can be seen in any area of life in the Arctic. They are especially noticeable in the transformation of natural capital, the traditional activities of indigenous peoples. But the problems of finding ways to 
achieve the eco-sustainability of the Arctic cannot be solved by a single country [7]. Therefore, international cooperation is the key to successfully solving the problems of sustainable development in the Arctic.

Thus, the topic of sustainable development of the Arctic ecosystem should be considered in a broad context, i.e. politics, economics, social sphere and ecology should be included. In fact, we are talking about a synthesis of multidirectional approaches and mechanisms for the purpose of a single Arctic sustainability.

\section{Analysis of Russian Arctic ecosystem sustainability: tendencies and perspectives}

The Russian Arctic strategy is aimed at realizing the national interests of the state in the northern hemisphere [8]. As the largest Arctic country, Russia has significant potential in strengthening its positions in the polar space. This is due not only to the huge reserves of natural resources, but also to the Northern Sea Route. The NSR is an alternative transport corridor for the delivery of goods between Europe and Asia [9]. Given the growing tensions in the southern latitudes over cargo security, the northern route is less risky, although it requires vessels suitable for Arctic waters, as well as appropriate personnel qualifications.

Russia's Arctic strategy takes into account the opportunities and threats associated with climate change. According to the logic of the strategy rationale, ice liberation makes the Arctic territories more accessible, which means it is necessary to strengthen the military presence. These trends are quite noticeable, there is an active modernization of military bases and the construction of new locations for the Arctic fleet.

However, the main goal of the implementation of the Arctic policy in the Arctic is to improve the living standards of people. The main task of the government is to stop the outflow of population from the northern territories, which began in the early 1990s and continues to this day (fig. 2). The main reason for the difficult socio-economic situation in the Arctic regions is the destruction of the social security system, which was in the USSR, the closure of many industrial enterprises, the bankruptcy of mines.

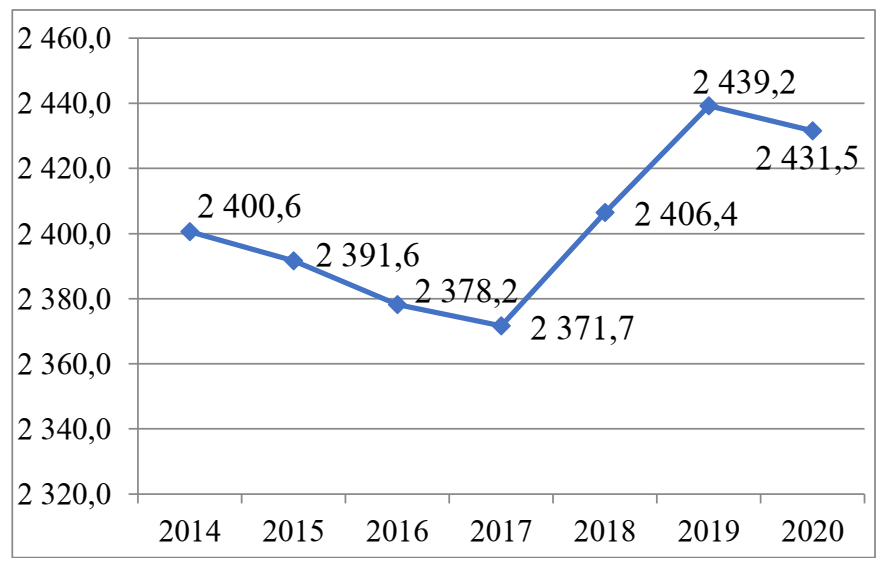

Fig. 2. Population of the Russian Arctic

Source: https://rosstat.gov.ru/storage/mediabank/xlFIQm1t/pok_86.xls

The Arctic is becoming less and less attractive region for life every year. Even the desire to stay is not affected by the level of income, which is much higher than the national average. But the cost of living in the Arctic is more expensive. The harsh climate, lack of 
modern infrastructure, dilapidated housing, complex logistics, transport inaccessibility, as well as high prices are becoming factors of negative migration. Modern research in the field of permafrost thawing confirms that a crisis in the Arctic infrastructure will occur in the future 40-50 years. Some changes are already noticeable in Yakutia and Yamal [10]. Insufficient funding also negatively affects the implementation of projects in the field of infrastructural development of the northern regions. This is especially true for life support facilities, social institutions. In this regard, the government faced the question of rethinking the essence of the Arctic policy, defining tasks that correspond to the realities in the geopolitical, socio-economic and environmental context.

The Russian Arctic strategy provides for the implementation of a set of tasks in several areas:

- social development, including medicine, social infrastructure, support for indigenous peoples;

- economic development: transport and logistics, subsoil use and technologies, economic regimes and taxes, state support for economic activity;

- infrastructural development: transport facilities, engineering solutions, communications and communications, energy projects;

- the development of science and technology: state support for research, the creation of scientific and educational centers, the creation and development of new materials for work and life in the Arctic, international projects and research;

- ecology: the elimination of accumulated environmental damage, the introduction of innovations in industrial production and other industries on the basis of "green" principles, the creation of unified state centers for the protection of Arctic ecosystems and their monitoring.

The Arctic strategy will be implemented in three stages, each of which contains the main directions of the progressive development of the polar regions:

1. Stage I (2020-2024): the formation of the regulatory framework for the functioning of the Arctic regions in the new conditions, the development of social security for the inhabitants of the Arctic; modernization of social infrastructure, creation of a satellite constellation to provide the Arctic space with communications and continuous monitoring.

2. Stage II (2025-2030): integrated development of cities and towns, increasing the competitiveness of the Arctic economy, the formation of human capital in the Arctic, new models of equipment, fleet.

3. Stage III (2031-2035): completion of the majority of state programs for the development and modernization of shipping, infrastructure, social services, energy supply, replacement of diesel equipment in hard-to-reach places with alternative energy sources, an increase in the capacity of enterprises in the field of subsoil use, but taking into account environmental safety requirements.

Among the target indicators for the implementation of Russia's Arctic strategy, one can conditionally single out economic, social and environmental ones. Among the economic indicators, an increase in capital investments in infrastructure facilities, an increase in investment, an increase in the volume of goods transported through the NSR up to 130 million tons are considered. Social indicators characterize human life in the Arctic: life expectancy, which should increase to 82 years, increase in jobs, attract young people to Arctic regions through the implementation of special social programs. Environmental targets are associated with an increase in investments in nature conservation, an increase in the share of alternative energy, and the introduction of innovations.

Currently, there is an increase in public investment in the Arctic zone, as evidenced by the data from Table 1 . 
Table 1. Investment in the Russian Arctic, mln rubles

\begin{tabular}{|l|l|l|}
\hline & \multicolumn{1}{|c|}{2019} & \multicolumn{1}{c|}{2020} \\
\hline Total investment, including: & 1449857846 & 1336657298 \\
\hline own funds & 508506459 & 941351387 \\
\hline loans & 679104042 & 657553256 \\
\hline
\end{tabular}

Source: https://gks.rulfree_doc/new_site/region_stat/arc_zona/2019_1/pok_17.xlsx

Changes in the sources of investment in Arctic projects are associated with various factors. First of all, Russia is partially limited in gaining access to international credit resources due to the introduction of financial and economic restrictions. To reduce the risk of disruption or delay in project implementation, the Russian government has increased the share of public funds.

It should be noted that with an increase in the number of projects being implemented in the Arctic, the costs of environmental protection, technologies for filtration, purification of air, water and soil grow (fig.3).

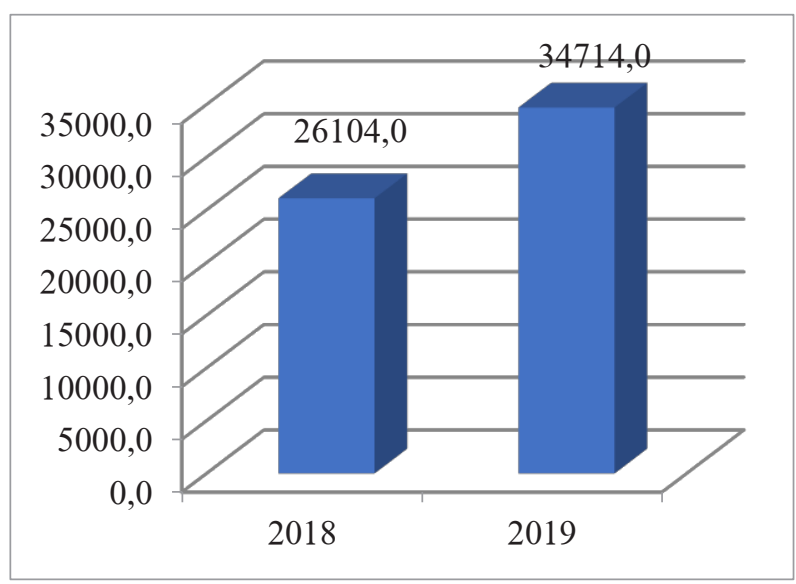

Fig. 3. Investment for the protection and rational use of natural resources in the Russian Arctic, mln rubles

Source: https://gks.ru/free_doc/new_site/region_stat/calendar1-2020.htm

According to the plan for Russia's chairmanship in the Arctic Council, the main task is to develop mechanisms for the transition to a low-emission economy. The Arctic must become a place for the application of innovations in industry, transport, communications and social infrastructure to make the life of people and ecosystems sustainable.

\section{Conclusions}

1. The Arctic has been a center of attraction for the state, business, education and science for several decades. It is with the beginning of the 21 st century that we can talk about the breakthrough interest of various participants in the Arctic space. These are politicians, economists, ecologists and scientists. Many groups are involved in the development, use and conservation of the Arctic. Climatic changes, which are more and more noticeable in the Northern latitudes, lead to negative consequences. Increasingly, the question of providing for a person in the Arctic, his activities, including traditional management, arises.

2. The main mechanisms for ensuring sustainable development of the Arctic ecosystem are international cooperation, investment in environmental protection, and the 
dissemination of the most successful practices for preserving natural capital throughout the circumpolar space.

3. An important addition in ensuring the sustainability of the Arctic ecosystem is the achievement of a balance of interests of business and northern communities. The expansion of the area of industrial production largely leads to the emergence of conflicts, since the zones of stress are expanding, which means that traditional economy (reindeer husbandry, fishing, hunting) suffers. In such a situation, benefit sharing mechanisms are able to solve the problem of compensation for losses of indigenous peoples by creating funds to invest in projects for sustainable development of the territory [11].

\section{Acknowledgements}

The article has been prepared by the financial support of RFBR No. 20-010-00252.

\section{References}

1. V. Gassiy, V. Stoikov, E3S Web of Conferences, 177, 04005 (2020)

2. Blue Bioeconomy in the Arctic Region, SDWG Arctic Council (2019) https://oaarchive.arctic-council.org/

3. Lynge, Climate change and Arctic sustainable development: scientific, social, cultural and educational challenges, 376 (2009)

4. Southcott F. Abele, D. Natcher, B. Parlee, Resources and Sustainable Development in the Arctic, Routledge, 314 (2020)

5. C.A. Monz, K.J. Gutzwiller, V.H. Hausner, M.W. Brunson, R. Buckley, C.M. Pickering, Ambio, 50, 631 (2021)

6. T. Koivurova, Environmental protection in the Arctic and Antarctica, Polar Law Textbook (2011)

7. K. Mohn, The Energy Journal, 40, 3, 199

8. Strategy for the development of the Arctic zone of the Russian Federation and ensuring national security for the period up to 2035, Decree of the President of the Russian Federation of October 26, 2020 N 645, official website of the President of the Russian Federation http://www.kremlin.ru/

9. O.S. Moe, Arctic Review on Law and Politics, 10, 24 (2019)

10. Fedorov, N. Vasilev, et al., Geosciences, 8(12), 465 (2018)

11. V. Gassiy, I. Potravny, Resources, 8(2), 71 (2019) 